\title{
RESEARCH ON THE POLICIES AND LAWS OF INTERNATIONAL CIVILIAN REMOTE SENSING SATELLITES AND THEIR PROBLEMS
}

\author{
Xiaopeng Zhang ${ }^{1,2, *}$, Weiye Wan ${ }^{2}$, Guoqing Zhou ${ }^{1}$, Tao Yue ${ }^{1,3}$, Bing Chen ${ }^{4}$ \\ ${ }^{1}$ Guangxi Key Laboratory of Spatial Information and Geomatics, Guilin 541004, China - xiaopeng.zhang@glut.edu.cn; \\ ${ }^{2}$ College of International Education, Guilin University of Technology, Guilin 541004, China - (xiaopeng.zhang, fao)@glut.edu.cn \\ ${ }^{3}$ College of Geomatics and Geoinformation, Guilin University of Technology, 12 Jiangan Rd, Guilin, China - yuetao@glut.edu.cn \\ ${ }^{4}$ Nanning University, Nanning 530200, China-54316149@qq.com
}

KEY WORDS: Civilian Remote Sensing Satellite, International Policies and Laws, International Legislations, Issues Research

\begin{abstract}
:
In the exploration of outer space and international space activities, civilian remote sensing satellites have made rapid development since the 1970s, and countries around the world have accelerated their civilian satellite development and its policy formulation as well. Regarding the regulations on the peaceful use of outer space and related space launches, the United Nations respectively formulated the "Five Treaties on Space" in the 1960s and 1970s to regulate the peaceful uses of outer space. However, in the development of civilian remote sensing satellites, orbital resources and application rules of remote sensing data, the implementation of "first-come, first-occupy" and "non-discriminatory access to remote sensing data" is mainly led by western developed countries, especially the space powers such as the United States and Russia. Based on the outer space policies and regulations, this article will make a comparative study of civilian remote sensing satellite development policies and related laws and regulations in major countries and regions in the world, so as to analyze the policies and legal principles of civilian remote sensing satellites, as well as its corresponding issues and problems.
\end{abstract}

\section{CURRENT INTERNATIONAL RULES FOR INTERNATIONAL REMOTE SENSING SATELLITES}

With the continuous development of artificial satellite technology, the demand for civilian satellites has also increased. It is mainly used in scientific detection and research, weather forecasting, land resource surveys, land use, regional planning, communications, tracking, navigation, and commercial fields. It has made important contributions to the daily life of human beings and the development of science and technology. As of December 31, 2016, a total of 1,459 satellites in 59 countries around the world were operating in orbit (Satellite Industry Association of the United States, 2017), and it also made great achievements in the satellite service industry, satellite manufacturing industry, satellite launch service industry and ground equipment industry. With the emergence of outer space policies and regulations, the United Nations has formulated the so-called "Five Treaties on Space": the "Treaty on the Principles that Countries Should Follow in Exploring and Using Outer Space, Including the Moon and Other Celestial Activities" (1967, referred to as Outer Space Treaty), the Convention on the Registration of Objects Launched into Outer Space (1967, referred to as the Registration Convention), the Agreement on the Rescue of Astronauts, the Return of Astronauts and the Return of Objects Launched into Outer Space (1967, referred to as: Rescue Agreement), the Convention on International Liability for Damage Caused by Space Objects (1972, referred to as the Liability Convention), and the Agreement to Guide the Activities of States on the Moon and Other Celestial Bodies (1979, referred to as the Moon Agreement).

The treaties and related resolutions formulated by the United Nations are agreements that all countries must abide by in carrying out outer space activities and regulate the peaceful use of outer space at the world level. However, due to the different levels of economic and social development in various countries around the world, the rules on the use of outer space, especially in the development of satellites and related laws and regulations, are mainly implemented by a few western developed countries, especially the United States, Russia and other space powers. The preemption rules of "first come first served" and the policy of "non-discriminatory access to remote sensing data" (Stephen Hobb, 2008) show a certain power. At the same time, countries with certain strengths have also complied with development and formulated corresponding civilian remote sensing satellite development policies and regulations, but they have basically been formulated based on national interests, and have shown greater applicability and commonality of regulations. Differences and incompatibilities (Zhou Wei, 2004), especially in terms of the launch, development, orbit resources, and application rules of remote sensing data of civilian remote sensing satellites, have created major obstacles.

Under such circumstances, the research and sorting out of the treaties and resolutions promulgated by the United Nations and the policies and regulations issued by relevant countries in outer space and artificial satellites, especially in the development of civilian remote sensing satellites and the use of related resources appear to be of practical significance. This can improve the understanding of current space law; clarify the rules and regulations of countries participating in space and civilian remote sensing satellite activities, and get problems solved when there are orbital conflicts or frequency anomalies or contradictions in remote sensing applications. The legal principles and legal basis of the responsibilities shall be settled

* Corresponding author 
scientifically and reasonably to resolve the consequences of handling contradictions.

\section{STATUS AND ANALYSIS OF INTERNATIONAL CIVIL REMOTE SENSING SATELLITE POLICIES AND REGULATIONS}

\subsection{General International laws and regulations}

The international laws and regulations should be followed for the development of civilian remote sensing satellites include the United Nations Declaration on Outer Space, the Outer Space Treaty, the Principles on Remote Sensing the Earth from Outer Space, the International Telecommunication Union Organization Act, the International ITU Convention, ITU Radio Regulations, Rules of Procedure, Recommendations, etc. According to international regulations, countries have the right to peacefully explore and use outer space activities. The legal research on remote sensing satellites is divided into two parts: One, regulations on satellite launch, frequency use and orbit allocation. Radio frequency and satellite orbit are limited natural resources and must be used on an equal, reasonable, economic, and effective basis. Effective interference control mechanisms should be adopted to make full use of frequency and orbit resources. Second, regulations for remote observation and data applications for earth observation. The "soft law" with the mainstream of policies such as the "Principles on Remote Sensing the Earth from Outer Space" (referred to as "Remote Sensing Principles") issued by the United Nations in 1986 as "hard law" and the United States "non-discriminatory access to remote sensing data" Coexistence.

Some legal issues have arisen in the application of remote sensing satellite data, for example, the "Remote Sensing Principles" stipulated the basic principles of data collection, but the rights of remote sensing countries in remote sensing activities were not clearly defined; the "Remote Sensing Principles" did not completely resolve the acquisition of data , use, and the rights of data producers; the current legal system does not provide for clarity on liability issues; the Outer Space Treaty and the Liability Convention do not provide for the types of damage that satellite remote sensing should be liable for those engaged in remote sensing activities. It is unclear what kind of responsibility the state should bear. Stephen Hobb (2008) argues that the United Nations Committee on Outer Space Affairs should decide to adopt a consensus approach to make decisions and redefine controversial space provisions or use General Assembly resolutions to demonstrate the importance of certain key concepts of international space legislation, which may ease the problems and disputes over resources in civilian satellites.

\subsection{Policies and regulations for Chinese Civilian Remote Sensing Satellites}

China became a member of the Committee on the Peaceful Uses of Outer Space in 1980. According to international treaties such as international space law, the state agency in charge of the aerospace industry at the time, led by the Chinese Ministry of Aerospace Industry, formulated corresponding internal policies and administrative regulations to regulate Acts related to commercial communications (civilian) satellite launch services. In 2001 and 2002, China issued the Administrative Measures for the Registration of Space Objects and the Interim Measures for the Administration of Licenses for Civil Space Launch Projects, respectively, based on the United Nations' Five Space
Treaties and the ITU Radio Regulations, so as to regulate Chinese civil satellite launches and the use of orbital resources. However, China has a late start in the development and utilization of space resources, and its international competitiveness is relatively weak. The reserves of satellite frequency orbit resources cannot meet our needs (Zhang Yu et al., 2014).

In terms of satellite launch, frequency use, and orbit allocation, relevant experts' research on Chinese civilian satellites is mainly focused on the technical and application level, while the policies and laws and regulations on its frequency and orbit resources and comparative studies with foreign countries are less. They all focused on the dimensions of the space law framework and commercial satellite service policies, but less expansion of the legal basis and regulations of the "first-come, first-occupy” .

In terms of standardized management of the development of remote sensing satellites, China only mentioned the support policies for the development of remote sensing satellites and related constraints such as the release of pictures in some national documents, and stipulated the access requirements for the remote sensing satellite industry. Relevant national departments have successively issued the "Provisions on the Free Distribution of China-Pakistan Resource Satellite Data", "Several Opinions on Encouraging Domestic Users to Use China-Pakistan Earth Resource Satellite Data", "About ChinaPakistan Earth Resources Satellite 01/02 / 02B Star Domestic Data Management Regulations and other policies, but the policy is highly targeted, and there are still some gaps in the standardized management of the commercial remote sensing satellite industry and satellite data policies, affecting the sustainable development of the civilian remote sensing satellite industry. From a policy perspective, there is a lack of clear definition and regulation of the development of various types of satellite remote sensing systems, the application of remote sensing data, the access and export of remote sensing data at the national level. Domestic research on remote sensing satellites mainly includes three aspects: satellite manufacturing and launching, ground transportation control and measurement and control services, image processing, and commercial applications (Yang Dong et al., 2013). Therefore, the research on policies and corresponding regulations is basically based on these three aspects. In terms of exploration, expansion and strengthening, it is necessary to integrate the construction of systematic legislative and legal basis.

\subsection{Policies and Regulations of Civilian Remote Sensing Satellites in other countries}

Other countries have more detailed policies and regulations on space law and satellite launches, applications, frequencies and orbital resources, and international space law is increasingly showing a trend of "soft law" and "decentralization" (Wu Xiaodan, 2008). That, international law (soft law), is not legally binding but has certain legal effects, such as resolutions, decisions, declarations, recommendations, or standards of international organizations or international conferences. While, among which the frequency and orbital resources of civil satellites, relevant regulations have gradually been softened. The Radio Regulations formulated by the International Telecommunication Union (ITU) have relatively "hard" regulations for the registration and use of satellite frequencies and orbital resources. However, since satellite launches are mainly concentrated in a few countries, the United States, 
Russia and other space powers. The "coordination method" of "first-come, first-occupy" preempts track resources, and the "planning method" of "equal" distribution is rarely used $(\mathrm{Li}$ Jianxin, 2010). At present, countries led by aerospace powers such as the United States have formulated their respective space development strategic plans for the development of civilian satellites. Based on the framework of international space law and their respective legal benchmarks and reflecting their national interests and will, they have formulated and revised or continue the policies and regulations for the allocation of civil satellite frequency and orbit resources, which makes this legal system must reflect their own characteristics and different legal principles.

The United States leverages its technological leadership to influence foreign policy with its allies and non-aligned countries, and has therefore developed a "non-discriminatory access" policy for remote sensing data to encourage these countries to use US remote sensing satellite imagery. In 1984, the United States passed the first federal remote sensing regulation, the "Land Remote Sensing Business Act," which stipulated that the LANDSAT system should be operated by both the government and the private sector but the government should minimize its investment in the system with strict controls to the use of remote sensing data.

In the early $1990 \mathrm{~s}$, on the basis of full consideration of the commercial and national security interests of remote sensing systems, the U.S. Congress passed the second federal remote sensing regulation, the Terrestrial Remote Sensing Policy Act, in 1992, which promoted commercial remote sensing satellites Civilianization. The bill stipulated that the LANDSAT system should be returned to the government.

Since 2004, some remote sensing user groups in developing countries such as Argentina, Colombia, Malaysia, and Thailand have been expanding. However, some countries have voiced opposition to the need to spend huge amounts of money to build a remote sensing system. In order to fully reflect the social and economic value of remote sensing systems and ensure that existing remote sensing systems continue to operate, countries have begun to formulate relevant laws and policies.

The guarantee for the civilian development of remote sensing satellite data is generally in the form of laws or presidential decrees. National policies are issued to regulate the development of civilian remote sensing from the top level. The policy supports and regulates the development, use, output, and introduction of remote sensing data, which is the guarantee for the continuous development of remote sensing (Ge Bangjun, 2012). Civilization and commercialization of international remote sensing satellites have formed a certain scale, highresolution remote sensing data has continuously entered the market, data acquisition has become more and more international, and the resolution has continued to increase. The policy encourages domestic development of no less than international commercial and commercial resolution data, as well as free and equal use of the remote sensing system owned by the state and government to the public within the scope of the policy..

\section{PROBLEMS WITH THE CURRENT LEGAL FRAMEWORK}

At present, there are fewer laws on the distribution of remote sensing data in various countries around the world, mainly based on related policies. Some leading countries in the field of remote sensing, such as the United States and Canada, have enacted laws on remote sensing. The legislation on remote sensing in other countries is mostly based on the patterns of United States and Canada, such as South Korea and Germany, etc. Promulgated comprehensive laws and regulations on remote sensing and its data use. In addition, in countries that do not have remote sensing laws, the distribution of remote sensing data is mainly in accordance with other relevant national laws and regulations and satellite operation licenses signed with other countries. The current international legislation involving remote sensing has the following problems.

\subsection{General problems of the United Nations' Principles of Remote Sensing}

The United Nations' Principles of Remote Sensing stipulates the basic principles of data collection, but the rights of remote sensing countries in remote sensing activities are not clearly defined. This is manifested in the following: First, there is no geographical limitation on remote sensing activities, and the scope of observation includes natural resources, oceans, and areas beyond national jurisdiction; Second, prior to remote sensing, it is not required to consult with the remotely sensed country in advance to obtain the consent of the remotely sensed country. There is no need to notify the remotely sensed country in advance, and the remotely sensed country has no veto power. In addition, there are no restrictions on remote sensing capabilities, and there are no specific requirements for spatial resolution and the type of remote sensor (including radar or optics).

\subsection{Certain issues of the Principles of Remote Sensing}

The Principles of Remote Sensing have not completely solved the problems of data acquisition, use, and the rights of data producers. The twelfth principle of the Principles of Remote Sensing states that "Once the raw and processed data on the territory under the jurisdiction of the country under sensing is prepared, the country shall obtain such data on a nondiscriminatory basis at reasonable cost terms". "On the basis of non-discrimination" is generally interpreted as the responsibility of the sensing state to provide the sensing data to the sensing country under the same conditions as other countries wishing to obtain the sensing data. Therefore, there is no distinction between the purpose of the data and the user.

The "reasonable cost condition" is also a relatively vague concept. It is not defined in the Principles of Remote Sensing and can be interpreted differently. It can be either marginal cost or market price. Therefore, data pricing on different types of products and different uses is not instructive. Although the tenth and eleventh principles encourage the disclosure of information that is conducive to environmental protection and disaster reduction, there are no specific requirements for the provision of data. Therefore, there is no legal basis for using and sharing remote sensing data on favourable terms for the public interest.

The "Remote Sensing Principles" makes no provisions on the rights of data producers with respect to data, including intellectual property rights and conditions for data use. At present, data acquisition, distribution and use rules are mainly formulated by different data providers, and there is no uniform standard. 


\subsection{The current legal system does not provide clear provisions on liability}

The Outer Space Treaty and the Liability Convention provide international responsibility for damage to the Earth caused by space objects or components in the launching State. The Liability Convention stipulates that "the launching State shall bear the absolute responsibility for compensation for the damage caused to its space objects on the surface of the Earth or to aircraft in flight". From this point of view, the Liability Convention only addresses the issue of direct physical damage caused by space objects, that is, the physical damage caused by the accidental fall of remote sensing satellites on the surface of the earth.

The Outer Space Treaty and the Liability Convention do not provide for the types of damage that satellite remote sensing should be liable for. For example, in these two documents, no provisions were found on the provision of accurate information on remote sensing, the absence of errors in remote sensing information that could cause damage to others, and the liability for compensation for damage.

In addition, the rules regarding what kind of responsibility should be undertaken by countries engaged in remote sensing activities are unclear. According to the "Remote Sensing Principles", the scope of "remote sensing activities" is "remote sensing space systems, operation of raw data collection and storage stations, and activities that process, interpret and disseminate processed data". From this definition, it can be inferred that the responsibility of remote sensing only involves the processing and dissemination of data, but does not cover the use of data.

It can be seen that the provisions of the "Remote Sensing Principles" on "States that operate remote sensing satellites should assume international responsibility for their activities" do not require end users or any third party using the data to bear corresponding responsibilities. Responsibility is limited to the data provider. Therefore, the Principles of Remote Sensing did not solve the problem of responsibility of all parties in remote sensing activities, nor did it solve the problem of responsibility in the use of data..

\section{CONCLUSION}

Due to the different levels of economic and social development in various countries around the world, the rules for the use of outer space, especially in the development of artificial satellites and related laws and regulations, are mainly developed by a few western space power countries, which on a certain way has limited the development of international civilian remote sensing satellites. At present, many countries and even private companies have remote sensing technology and capabilities, and the release of data is more commercialized. Many non-state agencies have emerged in data production, processing and value-added services. Similarly, users of data are also showing a trend of diversification, including rescue agencies, United Nations organizations, universities, media, insurance companies and even individuals, all of which have demand for remote sensing data. The data are also used for a wide range of purposes, including damage assessment, confirmation of insurance claims, environmental research, and map production. However, the current legal framework can neither effectively promote nor effectively regulate remote sensing activities, and does not explicitly address the rights and responsibilities of all parties involved in the production, provision and use of data, especially business and operational issues, including data policy issues, data-related intellectual property issues, and liability issues.

\section{ACKNOWLEDGEMENTS}

This project was funded by Guangxi Key Laboratory of Spatial Information and Geomatics. (17-259-16-08)

\section{REFERENCES}

Satellite Industry Association (SIA)., 2017. State of the Satellite Industry Report, 2017.6

Stephen Hobb., 2008. 50 Years of International Space Law. Global Law Review, 2008.4.

Ge Bangjun., 2012. Enlightenment of foreign remote sensing policies on the development of commercial satellite remote sensing in China. Satellite Applications, 2012.4.

Yang Dong, Yao Lei, Shi Huifeng, Huang Xiang., 2013. Research on the Policy Status and Commercialization Development of Civil Remote Sensing Satellites in China. Military and civilian dual-use technology and products, 2013.9

Zhou Wei., 2004. On International Space Law and China's International Commercial Satellite Launch Services Policies and Regulations. China Aerospace, 2004.6

Zhang $\mathrm{Yu}$, Chen Yong, Liu Yongxiang, Jiang Huijuan, Wu Hao., 2014. Research on the Status and Utilization of US Satellite Frequency Orbit Resources. China Radio. 2014 (8)

Wu Xiaodan., 2008. Status and Development Trend of International Space Law. Journal of Beijing University of Aeronautics and Astronautics (Social Science Edition), 2008.9

Li Jianxin., 2010. Strengthening the Management of Frequency and Orbit Resources to Promote the Healthy Development of Satellite Application Industry. World Telecommunications, 2010.6

A. Kerrest., 1999. Remarks on the notion of launching state, in: IISL Proceedings of the 42nd Colloquium on the Law of Outer Space (1999), p. 308.

Gaysberta C.M. Reinan. Translated by Tan Shiqiu. Utilization of outer space and international law. Published by Shanghai Translation and Publishing Corporation, 1985129 - 301

Hamilton DeSaussure., 1989. Remote Sensing Satellite Regulation by National and International Law. 15 Rutgers Computer \& Tech. L.J. 351 (1989)

Matthew M, Lynn S, Daniel K. Large Landscape Conversation: A Strategic Framework for Policy and Action. Http: //www.america 2050.org/, 2010-06-10

\section{Revised November 2019}

